\title{
Liaison psychiatry for senior registrars
}

\author{
Report of a training conference
}

\section{Peter White, Department of Psychological Medicine, St Bartholomew's Hospital, London ECl}

The Liaison Psychiatry Group recently held its first training conference for 20 senior registrars. This report is an account of the conference held in Oxford last September.

Informal feedback from the SRs showed that the conference was useful and convivial. The conference was over-subscribed, being limited to 20 to enable small group discussion. This allowed the development of a cohesive atmosphere in spite of the different backgrounds of people. The mix of embryonic academics and clinicians, adult and child psychiatrists allowed a fertile exchange of ideas. The format allowed all SRs the opportunity to express themselves and facilitated an eclectic approach from the analytical, through the cognitive/behavioural, to the pharmacological. The two biggest problems met were when to fit in a visit to Blackwell's bookshop and how to define the subject of liaison psychiatry. Was it passive consultation or active liaison? Did it include liaison with both general practices and general hospitals? The consensus definition at this conference was both consultation and liaison with non-psychiatric hospital units.

Dr Richard Mayou assembled the great and the good of Oxford liaison psychiatry to speak. Richard Mayou took us through development from the first ward for "lunatics" in a general hospital at Guy's in 1728 , to the modern role of a liaison psychiatrist. Dr Ted Smith reviewed the well organised Oxford approach to deliberate self-harm. Dr Keith Hawton tackled the science of deliberate self-harm and the difficult task of suicide prediction.
Paul Salkovskis reviewed, and demonstrated by videotape, the use of cognitive behavioural therapy in "functional" disorders. He stressed the over-riding importance of engaging the patient and acknowledging the genuineness of their symptoms before working on their attribution. Robert Peveler reviewed the potential use of such techniques for knotty problems such as treatment compliance in patients with "brittle" diabetes.

Allan House managed to make a potentially dull two hour seminar, about setting up a consultation/ liaison service, into a fascinating and radical discussion about the role of psychiatry in a general hospital. A splendid dinner seemed to minimise any differences of opinion most amicably, at least by the time port was taken.

The last day was spent looking at the future with Susan Iles making research look easy. Hilary Warwick even more remarkably demonstrated a successful cognitive/behavioural treatment for the difficult problem of hypochondriasis.

Suggestions for improvement next time included asking a physician to talk about the usefulness of liaison psychiatry, widening the emphasis on clinical disorders (such as the recognition and treatment of depressive illness in the presence of a physical illness) and inviting speakers from other centres so that SRs could learn about alternative approaches. However, this was thought to be but fine-tuning of an excellent conference that was thought to be well worth attending.

\section{Spring holiday}

The College will be closed from 7.00 p.m. on Thursday, 25 May until 8.00 a.m. on Tuesday, 30 May 1989. 